
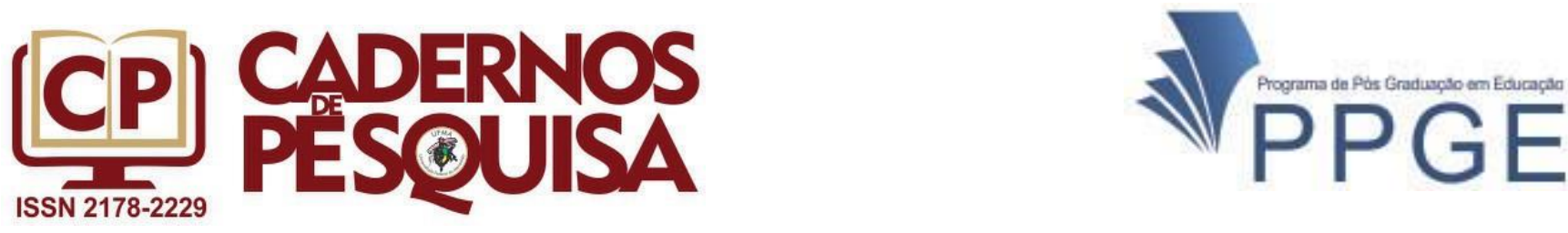

\title{
Educação Básica na Amazônia: as águas da diversidade inundando as escolas ribeirinhas
}

\section{Educación Básica en la Amazonia: las aguas de la diversidad inundando las escuelas ribereñas}

\section{Primary education in Amazonia: the waters of diversity flooding the riverside schools}

\author{
Márcia da Silva Carvalho ${ }^{1}$ \\ ORCID: org/0000-0003-2825-1517. \\ Maria do Perpétuo Socorro Cardos da Silva ${ }^{2}$ \\ ORCID: org/0000-0002-2574-4183.
}

Resumo: O presente artigo traz a importância da educação básica em conectar-se com toda biodiversidade do vasto território amazônico e as salas de aula atentando para a necessidade da formação inicial e continuada de professores de forma intercultural refenciando os cenários de diversidades amazônica. Os autores pautados trouxeram maresias de saberes para o presente estudo: Fleuri (2018), Oliveira(2016), Freire (1986), Giroux(2009), entre outros. Observa-se com estudos inicias em escola ribeirinha da liha de Paquetá/PA, que os professores passam por formações em conjuntos com toda a rede de ensino, não tendo uma formação e planejamento especifico para as escolas ribeirinhas, tendo que em suas horas pedagógicas adaptarem o planejamento global. Deve-se considerar sempre o ir e vir das águas, desobscurecendo a amazônia e identificando-a nos discursos, nos currículos de forma intercultural, minimizando a invisibilidade do povo das águas e todo seu potencial cultural.

Palavras-chave: Educação Básica. Diversidade. Interculturalidade. Amazônia.

Resumen: Este artículo trae la importancia de la educación básica en la conexión con toda la biodiversidad del vasto territorio amazónico y las aulas atentando a la necesidad de la formación inicial y continua de profesores de forma intercultural reflotando los escenarios de diversidades amazónicas. Los autores de las pautas han traído maresias de saberes para el presente estudio: Fleuri (2018), Oliveira(2016), Freire (1986), Giroux (2009), entre otros. Se observa con estudios iniciales en escuela ribereña de la Isla de Paquetá/PA, que los profesores pasan por formaciones en conjuntos con toda la red de enseñanza, no teniendo una formación y planificación específica para las escuelas ribereñas, teniendo que en sus horas pedagógicas adaptar la planificación global. Se debe considerar siempre el ir y venir de las aguas, desobscurendo la Amazonia y identificándola en los discursos de forma intercultural, minimizando la invisibilidad del pueblo de las aguas y todo su potencial cultural.

Palabras Clave: Educación Básica. Diversidad. Interculturalidad. Amazonia.

\footnotetext{
1 Pedagoga. Doutoranda e Mestre em Educação. Universidade do Estado do Pará. E-mail: marciacarvalho1967@gmail.com

${ }^{2}$ Licenciada em Letras. Mestre em Linguística e Dr. em Linguística. Universidade do Estado do Pará. E-mail: cardoso_socorro@yahoo.com.br
} 
Abstract: This article conveys the importance of primary education over connecting it with all the biodiversity of the vast amazonian territory and the classrooms, observing the necessity of basic and ongoing training of teachers in a intercultural manner referring to the diverse amazonian setting.The guiding authors to bring seas of knowledge to this study: Fleuri (2018), Oliveria (2016), Freire (1986), Giroux (2009), among others. It is noted with initial studies in riverside schools of Ilha de Paquetá/PA, that teachers go through general training with all the teaching network, not having a specific training or planning for riverside schools, having to use their pedagogical hours to adapt from a global planning. It must always be considered the ebb and flow of the waters, enlightening Amazônia and identifying it in the speeches and curriculums in an intercultural manner, uncloaking the water people and all their cultural potential.

Key Words: Primary Education. Diversity. Interculturality. Amazonia.

\section{EDUCAÇÃO BÁSICA NA AMAZÔNIA}

Não há saber mais ou menos: há saberes diferenciados!

(Paulo Freire)

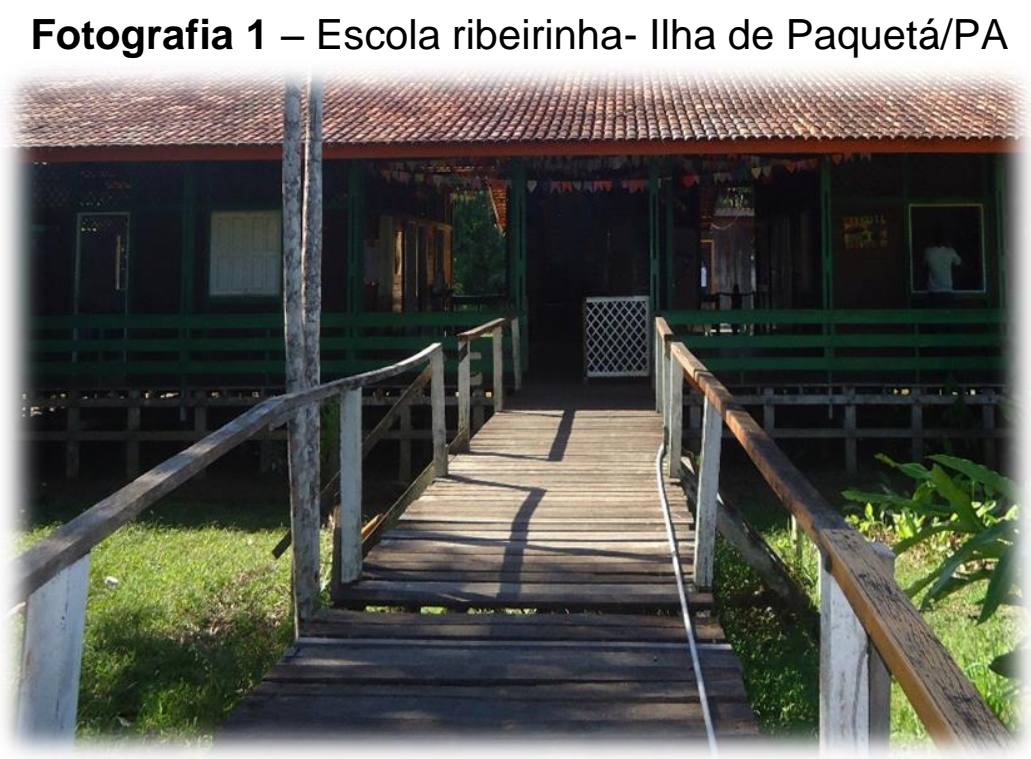

Fonte: Fotografia da Autora (2018).

A Amazônia se configura como cenário de grande biodiversidade e nos remete a um imaginário de amplitude, exuberância, imensidão. É esta imagem que se transfigura em realidade quando são percorridos os seus inúmeros rios, igarapés, lagos e furos. Porém, até mesmo quem é nascido nessa região não conhece sua totalidade, tamanha sua extensão e riqueza. Ainda tem muito de desconhecido na Amazônia.

Adentrar na educação tendo como referência a Amazônia é necessariamente adentrar por todos seu universo que banham as escolas ribeirinhas, onde este povo dos campos, mares e florestas se mostram como uma população que traz imerso 
toda complexidade de vivências e saberes desta vasta região e que com sua subjetividade faz emergir de suas águas toda cultura vivida em sua cotidianidade. Como ressalta Brandão (2003):

[...] pessoas, seres humanos que criam a vida que vivem, que vivem e pensam as suas próprias histórias que para eles tem, de fato, um sentido; histórias pessoais e coletivas de vida que desvelam pessoas e grupos humanos. (BRANDÃO, 2003, p. 91).

O conhecimento desta realidade amazônica é uma necessidade para que seja vista por outra ótica a educação na Amazônia, harmonizada com o seu contexto, com a natureza, com a sua cultura vivida, pois a harmonização homem e natureza são benéficas e produz qualidade de vida de toda ordem.

Tendo nestas conexões harmônicas um deslocamento que atravessa o olhar da cultura vivida dos ribeirinhos, sendo arrastado pelas águas ondulando os olhares até a escola a partir do seu cotidiano produtor de cultura como um interlocutor dialogando com a escola. Este deslocamento social e cultural, precisa estar representado na sala de aula, fazendo com que os alunos percebam seu cotidiano referenciando-o para uma reflexão crítica de sua realidade.

Numa cartografia amazônica desse cotidiano, vamos ter o trabalho como referência para o sustento das famílias todo vinculado a natureza, assim como a alimentação, a moradia, e nesta "rotina cultural" vai sendo estabelecida a cultura vivida dos ribeirinhos, nas águas e pelas águas.

Se nos remetemos ao entendimento de cultura como hábito a cultura amazônica tem seu cotidiano cultural produzido no seu dia a dia, quando remetem esta cotidianidade às marés que virão conforme a lua que se apresenta, a melhor posição do vento para sair nos barcos, o período de determinados peixes, frutas, entre outros hábitos dessa rotina cultural.

Ainda que o dia a dia seja vivido como uma rotina repetitiva, isto é construto cultural, como ressalta Paixão (2015, p. 530): "a cultura vivida, cultura com experiência vivida é composta por ações e expressões que retratam/refratam o acúmulo de saberes/conhecimentos dos sujeitos que derivam de leituras do campo empírico, bens simbólicos que são achados nas experiências cotidianas", cultura que altera seu cotidiano e é alterada por ele. 
O filosofo Homi Bhabha, usa o hibridismo como termo peculiar que pode-se remeter a educação amazônica, ribeirinha, como não poderia deixar de ser vindo das águas, são encharcadas de maresias, enchentes e vazantes, diversidades culturais, muitas vezes assimétricos como alerta Bhabha (2013):

A representação da diferença não deve ser lida apressadamente como reflexo de traços culturais ou étnicos preestabelecidos, inscritos na lápide fixa da tradição. A articulação social da diferença, da perspectiva da minoria, é uma negociação complexa, em andamento que procura conferir autoridade aos hibridismos culturais que emergem [...]. (BHABHA, 2013, p. 21).

Esse hibridismo apontado por Bhabha (2013) é observado quando se desloca para as alterações do rural para o urbano como relata Carvalho (2018, p. 52) um "deslocamento cultural recai sobre o cotidiano ribeirinho que vem encharcado de sua quietude e entra no cotidiano urbano cheio de acelerações, diferenças culturais que negociam e mesclam seus cotidianos" ainda Carvalho (2018, p.52) descreve essas mesclagens:

São hibridizações que aparecem com os acordos de venda das mercadorias (peixe, camarão, açaí) feitos pelo celular que só é usado quando se aproxima do continente, celulares que todos têm em suas casas, mas só usam quando saem da llha. Hibridismos que aparecem com o fenômeno da pirataria nos rios amazônicos, alterando assim os horários de saída dos pescadores que criam estratégia de saírem em pequenos comboios de barcos. (CARVALHO, 2018, p. 52).

As diversidades amazônicas exigem dos professores um saber voltado aos diversos cotidianos vivenciados neste, que é quase um continente geográfico, apresentando as vivencias ribeirinhas, caboclas, indígenas, quilombolas onde estes cotidianos se deslocam para as salas de aula.

Fotografia 2 - Fenômeno da Maré lançante

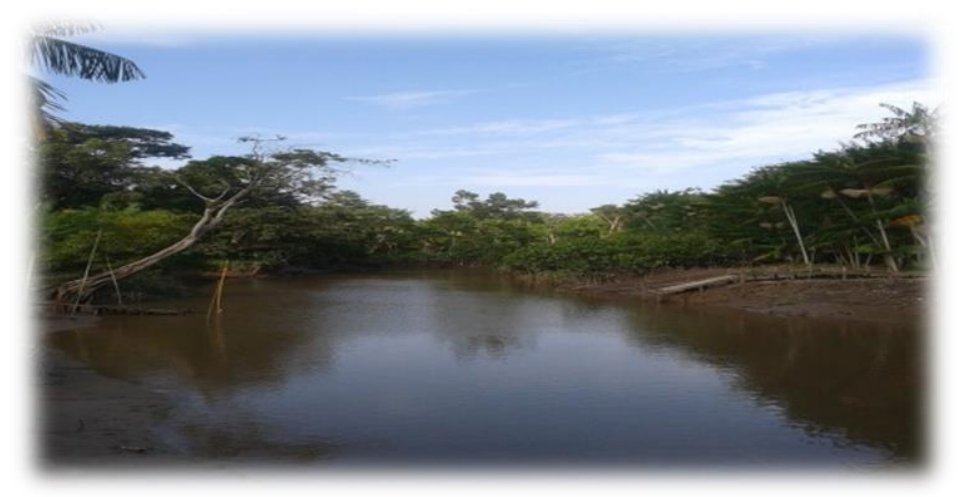

Fonte: Fotografia da Autora (2015). 
O fenômeno ${ }^{3}$ mostrado na foto acima, a chamada Maré Lançante, tem relação com determina lua, influencia na entrada e saída de barcos, ida e vinda de alunos na ilha de Paquetá/Pa, onde se localiza uma Unidade Pedagógica, a UP JAMACI. A referida maré permanece de 1 a 2 dias impossibilitando as aulas nesta unidade pedagógica, tal fato altera os calendários escolares, o planejamento dos professores, a rotina dos alunos, auxiliares da unidade, pais de alunos. Tudo precisa ser readequado após a Maré lançante. Trazemos neste momento a fala de um barqueiro, morador desta ilha Sr. M.S (76a) esclarecendo tal manifestação da natureza:

\begin{abstract}
A lançante (maré) escoa, escoa muito e somente barco pequeno é que entra no igarapé, fica arriscado por causa dos troncos de árvore, das raízes que ficam pra fora e trazer menino em barco pequeno de remo da mais canseira. Daí a gente quando vê que já vem dá essa maré a gente já avisa as professoras que não vai da pra entrar, né? Dai elas avisam os aluno que não vai ter aula. (M.S, 76르).
\end{abstract}

Os modelos tradicionais de currículo trazem de forma homogênea o saber distante do saber ribeirinho como apresenta Silva (2010), fazendo uma contextualização dos modelos tradicionais de currículo em décadas como a de 1960 e 1970, contudo, bem atuais ainda, quando as instituições não referendam um currículo que seja voltado ao contexto cultural heterogêneo e com isso fazem:

\begin{abstract}
Arranjos educacionais existentes às formas dominantes de conhecimento, ou de modo mais geral à forma social dominante. Ao tomar o status quo, como referência desejável, as teorias tradicionais se concentravam pois, nas formas de organização e elaboração do currículo. Os modelos tradicionais de currículo restringiam-se a atividade de como fazer o currículo. (SILVA, 2010, p. 29-30).
\end{abstract}

Estes arranjos vão invisibilizando a cultura amazônica nas escolas ribeirinhas que, como diz Freire (1987), vão desconectando os alunos de sua realidade criando "retalhos de realidade" e ainda Freire (1987, p. 58) ressalta que os alunos são "vasilhas" em recipientes a "serem enchidos", e completa:

Desta maneira, a educação se torna um ato de depositar, em que os educandos são depositários e o educador o depositante [...] na visão "bancária" da educação o "saber" é uma doação dos que se julgam sábios aos que julgam nada saber. (FREIRE, 1987, p. 58).

\footnotetext{
${ }^{3}$ * Os relatos e situações apresentados neste artigo na llha de Paqueta e Unidade Pedagógica do Jamaci, fazem parte de pesquisa de doutoramento em andamento na Universidade do Estado do Pará-UEPA.
} 
Assim Freire (1980, p. 66) denuncia a situação da educação como "um sistema precário e seletivo de educação, no qual as escolas são um instrumento para manter o 'status quo'; por altas porcentagens de analfabetismo". Este anuncio/denuncia faz reverberar as padronizações e homozenizações realizadas na escola onde este padrão é referenciado por uma visão dominante e eurocêntrica de mundo e sociedade.

E essa tomada de consciência se daria a partir do reconhecimento de sua cultura e suas identidades através da reflexão crítica de sua realidade, buscando através dela dar significado ao aprendido em sala de aula. Tendo como concepção de educação, a conscientização e o diálogo, categorias que trariam para os debates árduos embates com a concepção tradicional bancária de educação. Assim Freire (1980), anuncia os primeiros passos: "Essa tomada de consciência não é ainda a conscientização, porque esta consiste no desenvolvimento crítico da tomada de consciência" e vai seguindo o anúncio da descoberta da consciência.

\begin{abstract}
A conscientização é, neste sentido, um teste de realidade. Quanto mais conscientização, mais se "des-vela" a realidade, mais se penetra na essência fenomênica do objeto, frente ao qual nos encontramos para analisá-lo [...] A conscientização não pode existir fora da "práxis", ou melhor sem o ato ação-reflexão. (FREIRE, 1980, p. 26).
\end{abstract}

Porém a escola vem reafirmando relações eurocêntricas em suas salas de aula quando não legitimam em seus currículos os saberes locais, saberes populares, os nossos saberes amazônicos, impondo nos currículos uma invisibilidade da histórias dos povos das águas, como reforça Santomé (2009, p. 161), referindo-se as vozes ausentes na seleção da cultura escolar:

Quando se analisam de maneira atenta os conteúdos que são
desenvolvidos de forma explicita na maioria das instituições escolares e
aquilo que é enfatizado nas propostas curriculares, chama fortemente a
atenção a arrasadora presença das culturas que podemos chamar de
hegemônicas. As culturas ou vozes dos grupos sociais minoritários e/ou
marginalizados que não dispões de estruturas importantes de poder
costumam ser silenciadas.

O olhar dado para a Amazônia soa com lugar exótico, primitivo, ausência da modernidade, porem o cotidiano amazônico é produtor de culturas e tecnologias hibridas que com suas águas trazem ondulações claras de modernidade, contemporaneidades, Oliveira (2016) analisa que a modernidade numa visão 
eurocêntrica referenda a civilização europeia, como sendo o centro de excelência de desenvolvimento e emancipação e subalterniza as demais culturas.

$\mathrm{Na}$ lógica eurocêntrica os ribeirinhos são vistos como primitivos, a modernidade não os atinge, portanto seu desenvolvimento, sua emancipação não se concretiza, sendo assim e os ditos civilizados que passaram por todo processo de emancipação com a modernidade se tornam superiores, legitimando assim que estes subalternizem os primitivos, encobrindo esta cultura não desenvolvida, Oliveira (2016, p. 87) aponta "a experiência europeia do descobrimento se reveste na forma da negação e de encobrimento do Outro [...]. O índio não foi descoberto como Outro, e sim reconhecido como o mesmo, mas diferente". Esta dominação subjuga uma cultura em detrimento de outra.

O outro negado na sua identidade tendo sua cultura desconsiderada como legítima, não se vê como produtor cultural, se subjugando, não vendo necessidade de se qualificar para além de estritamente necessário, como podemos perceber no relado de Sr. R.N (58a):

Desde pequeno nunca achei necessidade de estudo, já que o que eu fazia num carecia muito conhecimento. A gente mal sabia escrever o nome e já estava bom. Os pais da gente só mandavam nós pra escola pra saber escrever o nome, depois num carecia mais, voltava pro açaizal. Agora não, eu mando os meus meninos pra escola desde cedo. (R.N, 58a).

Fotografia 3 - Pescadores preparando os matapis e redes de pesca

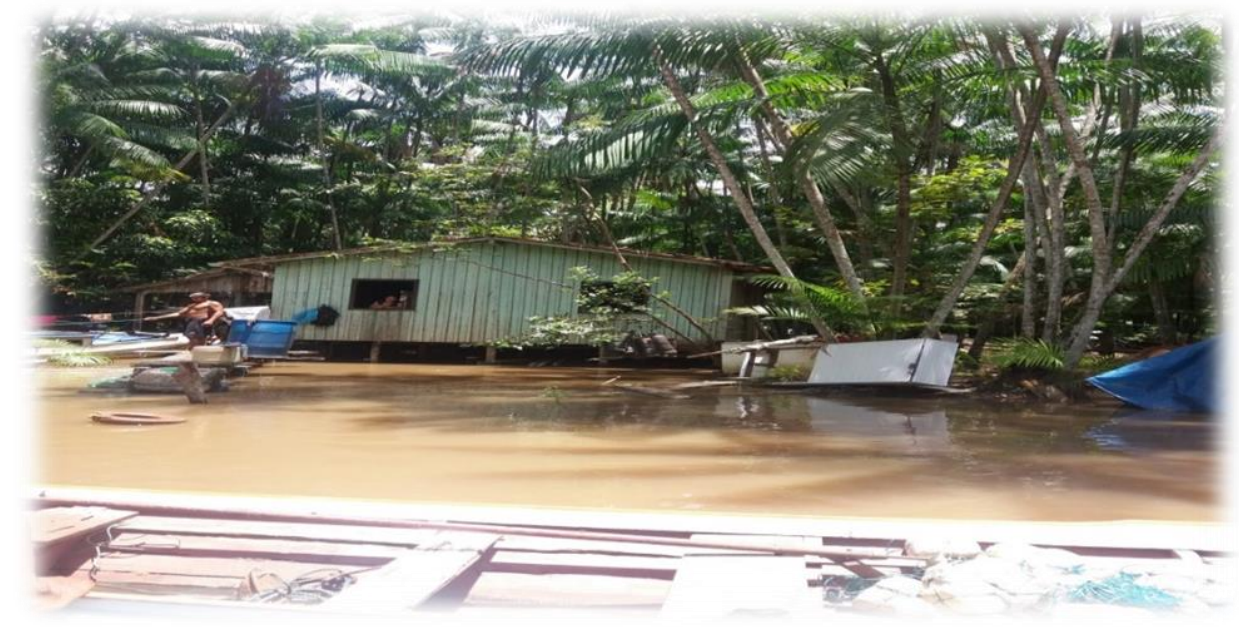

Fonte: Fotografia da Autora

Cadernos de Pesquisa, São Luís, v. 28, n. 4, out./dez, 2020. 
Se faz necessário o olhar voltado para a relação professor e aluno, onde a amorosidade, a aprendizagem significativa superem desafios cotidianos, sejam eles políticos, econômicos, sociais, geográficos, culturais pelas dificuldades apresentadas em se fazer educação na Amazônia. Desafios que a força das águas podem arrebatar quando não são deixados a margem o povo das aguas submetidos a imposições de aculturamentos, desprovimentos e vulnerabilidade.

2 EDUCAÇÃO INTERCULTURAL: navegando nas águas da diversidade

Fotografia 4 - Crianças das Ilhas- Unidade Pedagógica Jamaci/PA

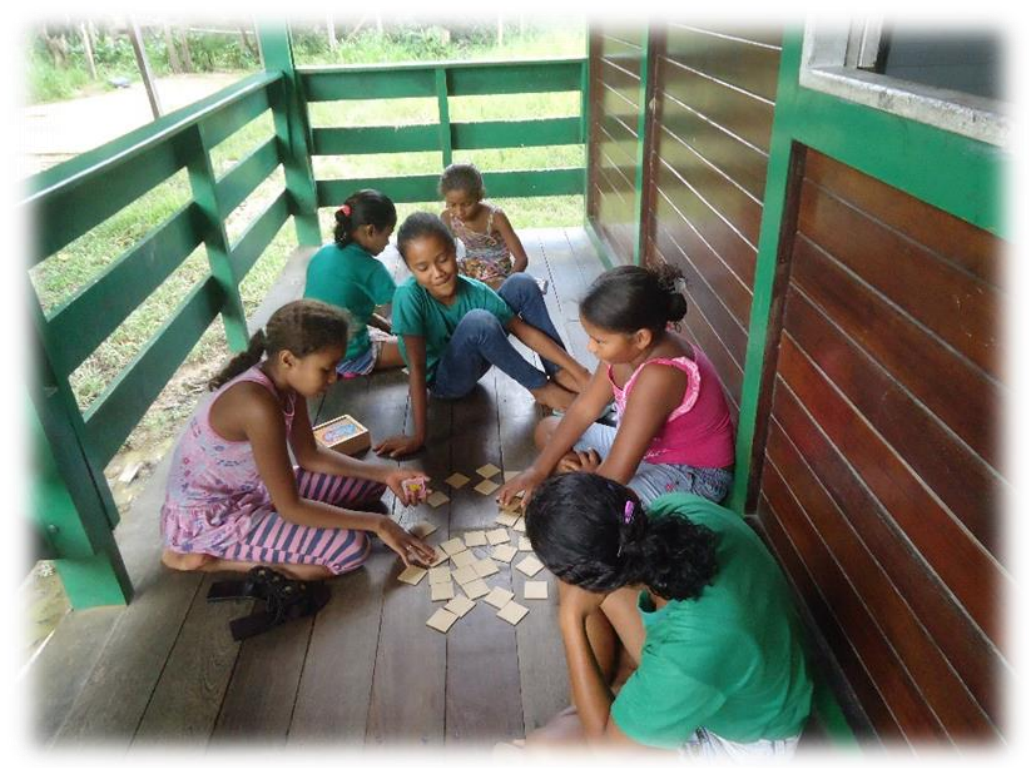

Fonte: Fotografia da Autora (2018).

As relações sociais na contemporaneidade nos anunciam a necessidade de novas maneiras na educação de construir o conhecimento buscando na diversidade cultural a perspectiva de se relacionar com todos os saberes. Buscamos aqui na perspectiva da diversidade nas relações culturais enfocar a Educação Intercultural nas práticas pedagógicas.

Nessa perspectiva intercultural somar campos de intervenção nestas práticas educacionais representa tomar a escola como palco central de atuação, buscando em seus territórios curriculares, avaliativos, metodológicos, espaços para que as 
diversidades culturais emerjam e sua materialidade se dê no processo de ensino e aprendizagem.

Pensar e agir na educação com enfoque intercultural é entender a escola como campo fecundo de simbolismo, como diz Costa (1998, p.38) pode-se entender "as escolas e seus currículos como territórios de produção, circulação e consolidação de significados, como espaços privilegiados de concretização da política da identidade" e assim ir buscando ambientes culturais fluidos, plurais.

A referência dos saberes trazido pelos alunos demonstra como a cultura amazônica encharca a escola, trazemos o relato de M.S (9a) conta situação vivenciada na família fazendo alusão a lara que lê nos livros da escola, com entusiasmo começa:

Meu tio acordou de noite abriu a janela, porque sua rede era bem em frente, e viu a lara, ele queria chamar minha vó que dormia na rede do lado dele, mas a voz dele não saia. Foi que a lara fez um redor nele e prendeu a voz dele. Ela tava querendo ele como namorado dela. Ai ele conseguiu gritar e ela sumiu" ela dá continuidade "Outra vez ele sempre ouvia um ronco em baixo da terra, era a lara que cantava, meu tio foi pra de baixo da casa atrás daquele ronco, foi, foi, foi e viu um buraco quando viu subiu uma fumaça pra cima dele e ele saiu correndo e ficou se coçando muito. Minha mãe levou ele na mulher que curou ele de coceira, ela passou um remédio e toda coceira passou e ela disse que era a lara querendo levar ele com ela. Puxando bem a respiração Miliele me olha satisfeita de suas histórias, e eu mais ainda por ouvi-la. (M.S, 9a).

A referida aluna relata uma história que não está nas páginas dos livros da biblioteca da Unidade Pedagógica do Jamaci, ou melhor, não na forma que estão escritas nos livros, fazendo alusão a lara como uma linda mulher branca a beira de uma praia com um canto inebriante.

Contribuindo para a necessidade de trazer a diversidade como aspecto pedagógico os Parâmetros Curriculares Nacionais para o Ensino Fundamental aponta a Pluralidade Cultural como temática transversal fundante para a busca de identidades que valorizem nossa diversidade étnicas e culturais. Esta temática traz um discurso alastrado socialmente de democracia racial, que dificulta a discussão da diversidade como demostra os Parâmetros Curriculares Nacionais para o Ensino Fundamental (BRASIL, 1997, p. 20) em sua justificativa:

Historicamente, registra-se dificuldade para se lidar com a temática do preconceito e da discriminação racial/étnica. O País evitou o tema por muito tempo, sendo marcado por "mitos" que veicularam uma imagem de um Brasil homogêneo, sem diferenças, ou, em outra hipótese, promotor de uma suposta "democracia racial". Na escola, muitas vezes, há manifestações de 
racismo, discriminação social e étnica, por parte de professores, de alunos, da equipe escolar, ainda que de maneira involuntária ou inconsciente. Essas atitudes representam violação dos direitos dos alunos, professores e funcionários discriminados, trazendo consigo obstáculos ao processo educacional, pelo sofrimento e constrangimento a que essas pessoas se veem expostas. (BRASIL, 1997, p. 20).

Esta intencionalidade de embranquecer o povo brasileiro trazida desde os primórdios do colonialismos europeu negou nossas raízes negras, indígenas, caboclas, dificultou ações, projetos e propostas educativas que tratassem sobre as identidades e relações culturais e a educação básica através de seus currículos, livros didáticos e avaliações, foram reforçando esta visão eurocêntrica de homogeneidade.

A educação básica vai se defrontando em suas salas de aula com o desafio de produzir práticas pedagógicas inclusivas a partir das diversidades culturais de seus alunos e alunas e de toda ordem de diversidades sejam elas, étnicas, sexuais, religiosas, geracional, de gênero.

As incursões feitas por Oliveira (2016) traz a denúncia/anuncio da cultura eurocêntrica que se define como superior e desfaz das ditas culturas débeis e imaturas, esta imaturidade precisa de um colonizador que virá a custo da modernidade estabelecer seus parâmetros de avanço, impondo sua cultura, valores e superioridade.

Assim Oliveira (2012, p. 58) ratifica "A colonialidade do saber operou a inferioridade de grupos humanos não europeus do ponto de vista da produção da divisão do trabalho, do salário, da produção cultural e dos conhecimentos", cegando e reprimindo outras formas de saberes, como os que são transmitidos nestas ilhas pela oralidade, histórias vivenciadas ou não por eles, mas com todo o imaginário e representações populares que como ainda salienta Oliveira (2016, p.230) “ produzidos nas práticas sociais e culturais e que refletem formas de viver, pensar e compreender o mundo".

Na perspectiva Intercultural de Educação reconhecer e valorizar a diversidade cultural, porém como ela tem suas raízes nos movimentos sociais de luta contra os processos de exclusão e opressão, pleiteia um reconhecimento das diferenças culturais problematizando-as, trazendo para o debate, como salienta Fleuri (2018, p. 39): 
A perspectiva intercultural da educação pode, ainda, estimular os movimentos a focalizar na própria reflexão e na própria prática, a dialética identidade/alteridade. Ou seja, estimular a consciência das diferenças e das relações entre os agentes e os pontos de vista que nele se articulam. (FLEURI, 2018, p. 39).

Essa capacidade de evidenciar as diversidades, distinguir as diferenças e criar as possibilidades de interação e resistência aos discursos discriminatórios, excludentes e opressores, caracteriza a educação intercultural diferenciando-a dos discursos, multiculturais, pois Fleuri (2018, p. 43) evidencia "a educação intercultural não se reduz a uma simples relação de conhecimento trata-se da interação entre sujeito" podendo estar sendo estimulados nas salas de aula na medida em que estimula relações de troca, de reconhecimento de direitos e dignidade.

Os discursos multiculturais buscam adaptar proposta educativas concebendo a diversidade cultural como um fato histórico, se toma consciência e adapta-se a ele, como demonstra Nanni (1998, p.30) "limita-se a coabitação das diferenças culturais como um processo histórico natural". Desloca-se para a perspectiva intercultural quando a intencionalidade na ação educativa se dá através de projetos de intervenção buscando a resistência e alteração das práticas excludentes e discriminatórias. Logo toma-se consciência das diferenças e modifica-se com ela.

$\mathrm{Na}$ educação intercultural a relação entre os sujeitos suas culturas e identidades se dá sem se negar as diferenças, os conflitos, porém acolhendo e estabelecendo uma pratica coletiva de discussão fluida, como referência Fleuri (2018, p.44):

\footnotetext{
A educação intercultural se configura como uma pedagogia do encontro até suas últimas consequências, visando a promover uma experiência profunda e complexa, em que o encontro/confronto de narrações diferentes configura uma ocasião de crescimento para o sujeito, uma experiência não superficial e incomum de conflito/acolhimento. (FLEURI, 2018, p. 44).
}

Mostra-nos uma multidimensionalidade da educação a partir das culturas e identidades do sujeito onde o ser se estabelece em todas as suas experiências, cultura vivida, cotidiano, territorialidades, dando luz as diferenças, não obscurecendo as culturas, permitindo o diálogo e as conexões entre elas. 
3 FORMAÇÃO DE PROFESSORES: deslocamentos necessários para formação inicial e formação continuada

Professores e professoras em seus processos de formação são exigidos quanto as áreas de conhecimentos e seus inúmeros conteúdos, os currículos densos, no sentido de quantidades de temáticas. Currículos estes, que estão à margem da realidade dos alunos não fazendo conexão com suas vivencias, saberes e experimentações.

É comum verificarmos que a qualificação de profissionais da educação em seu processo formativo, seja na graduação, ou na atuação profissional, uma padronização de comportamentos voltados para a busca de habilidades e competências e não de analises, entendimentos, sensações, visão de mundo, sentimentos que busquem estimular 0 aluno a reflexões e produção de conhecimento e não somente acumulo de conteúdo.

Tradicionalmente dos professores é exigido repasse de conteúdo das disciplinas, avaliações objetivas e relatórios quantitativos de produtividade de sua turma. Em seu artigo intitulado Praticando Estudos Culturais nas Faculdades de Educação de 2009, Giroux questiona, qual a causa dos Estudos Culturais terem ganhado popularidade, porém não serem incorporados pelos docentes e levanta algumas indicações:

Em parte essa indiferença pode ser explicada pelos estreitos modelos tecnocráticos que dominam os esforços convencionais de reforma e que estruturam muitos programas de educação. Pode-se creditá-la, ainda, a uma história de reforma educacional abertamente voltada para considerações práticas que, com frequência, se baseiam numa longa tradição de anti-intelectualismo. (GIROUX, 2009, p. 85).

Numa perspectiva de buscar qualificar o aluno para que este possa ser um sujeito reflexivo e critico referenciar os saberes, cultura, relações sociais, o cotidiano destes tem profunda importância nas salas de aula, onde a partir de tais cenários de debates problematizadores e construção de conhecimento, gerem uma atitude de intervenção diante das inúmeras situações vivenciadas pelos eles, sejam ela de violência, de pobreza, desemprego e outras tantas disparadas pela sociedade capitalista que desiguala classes, desnivela oportunidades criando processos de exclusão de toda ordem. Ainda no artigo citado, Giroux (2009, p. 85) sugere: 
Além disso a tradição dominante favorece a contenção e a assimilação das diferenças culturais, em vez de tratar os/as estudantes como portadores/as de memórias sociais diversificadas com o direito de falar e de representar a si próprios na busca da autodeterminação. (GIROUX, 2009, p. 85).

No campo dos Estudos Culturais a perspectiva a pontada é a não desvinculação dos conteúdos desenvolvidos nas disciplinas obrigatórias, convencionais, das discussões de questões sociais que gerem espaços narrativos e reflexivos afirmando a intencionalidade política no ato de ensinar e não a suposta neutralidade, que gere somente subordinação do aluno aos conteúdos padronizados, tendo em vista as relações históricas de uma educação excludente, como ressalta Giroux (2009, p. 86 ):

Corporificando formas dominantes de capital cultural, a escolarização frequentemente funciona para afirmar as histórias eurocêntricas e patriarcais, as identidades sociais e as experiências culturais dos/as estudantes da classe média, ao mesmo tempo que marginaliza ou apaga as vozes, as experiências e as memórias culturas dos/as assim chamados estudantes da "minoria". (GIROUX, 2009, p. 86).

A formação de professores, seja no Ensino superior onde os acadêmicos estão sendo formados para atuarem nas salas de aula, seja nas escolas da educação básica com os professores/as em atuação, estão sendo preparados com um enquadramento de nacionalidade, uniformização e padronização e não alargando esta formação para as discussões das diversidades. A formação inicial e/ou continuada demonstra um afastamento de teoria e prática, realidade, conteúdo e sala de aula.

Este afastamento resulta numa grande confirmação eurocêntrica educacional, onde os elementos culturais e identitários não aparecem no processo de ensino e aprendizagem. Pelo contrário reafirmam, legitimam, cada vez mais as referências colonizadoras europeias. A sala de aula passa a ser o desenvolvimento de competência e habilidades individuais, enquanto que as questões que podem ser discutidas no coletivo, por terem reflexo nas relações sociais, são deixadas de lado, afastadas.

O momento de construção do conhecimento entre os sujeitos cognoscentes, professor e aluno necessita de mediação e integração Freire $(1986$, p. 46) nos aponta "A educação libertadora é, fundamentalmente, uma situação na qual tanto os professores como os alunos devem ser os que aprendem", para que o momento de 
produzir e conhecer não se tornem transferências de um currículo oficial padronizado e Freire (1986) continua "tanto os professores quanto os alunos sejam agentes críticos do ato de conhecer", suscitando a necessidade de uma educação libertadora.

$\mathrm{Na}$ cartografia das águas que está sendo realizada na llha de Paquetá a voz dos professores começa a ecoar mostrando que a formação continuada na rede municipal de Belém aponta para uma formação generalizante e mesmo tendo a realidade das escolas nas ilhas, não se estabelece momentos específicos, para a formação destas, é o que nos mostra a professora N.N (35 a) da Unidade Pedagógica do Jamaci:

Nós é que fazemos as adaptações deste plano, nas nossas HPs (horas pedagógicas), pois ele é igual para todas as escolas da rede, porém aqui no Jamaci não temos como seguir a realidade das escolas da sede e nem das demais. Adaptamos até conforme as marés que quando é a maré lançante não entra barco no igarapé. $E$ isso os alunos já sabem juntamente com os barqueiros e logo nos avisam.

A referida professora declara ainda que mesmo os alunos demonstrando interesse por um determinado gênero textual: histórias em quadrinho, o Pacto Nacional pela Alfabetização na Idade certa/PNAIC e as avaliações nacionais, como a Provinha Brasil, estipulam as leituras que são obrigatórias para os alunos que participam desta avaliações nacionais sendo elas: Menina bonita do laço de fita, Camilão, o comilão. Algumas iniciativas espontâneas da referida professora, como, fazer uma assinatura de revistas em quadrinho e deixar a disposição das crianças são verificadas como formas isoladas para estimulá-las.

Fotografia 5 - Biblioteca Unidade pedagógica do Jamaci

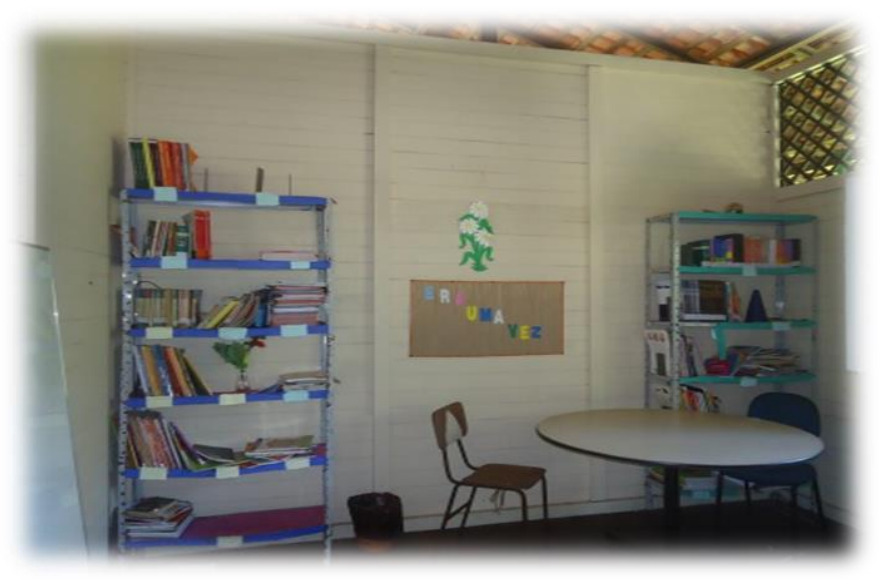

Fonte: Fotografia da autora 
As características do cotidiano nas escolas ribeirinhas feitas por $\mathrm{N} . \mathrm{N}$ (35a) alertando para estes territórios, pois a região e suas geografias apontam um desenvolvimento físico das crianças diferenciando seu desenvolvimento motor, das crianças urbanas, pelo fato de subirem em arvores, nadarem constantemente, remarem desde pequenos e andarem em pontes roliças feitas da arvores do açaí. Estas observações quanto a desenvoltura corporal das crianças ribeirinhas é salientada pela professora:

[...] em escolas urbanas onde trabalhei é preciso muito mais atividades que desenvolvam o equilíbrio nas crianças da educação infantil do que nas escolas ribeirinhas, por conta delas terem no convívio com a natureza estas habilidades muito mais desenvolvidas, além do senso de direção e mira [...]. (N.N, 35a).

Fotografia 6 - Caminhos de ponta trilhados diariamente pelas crianças

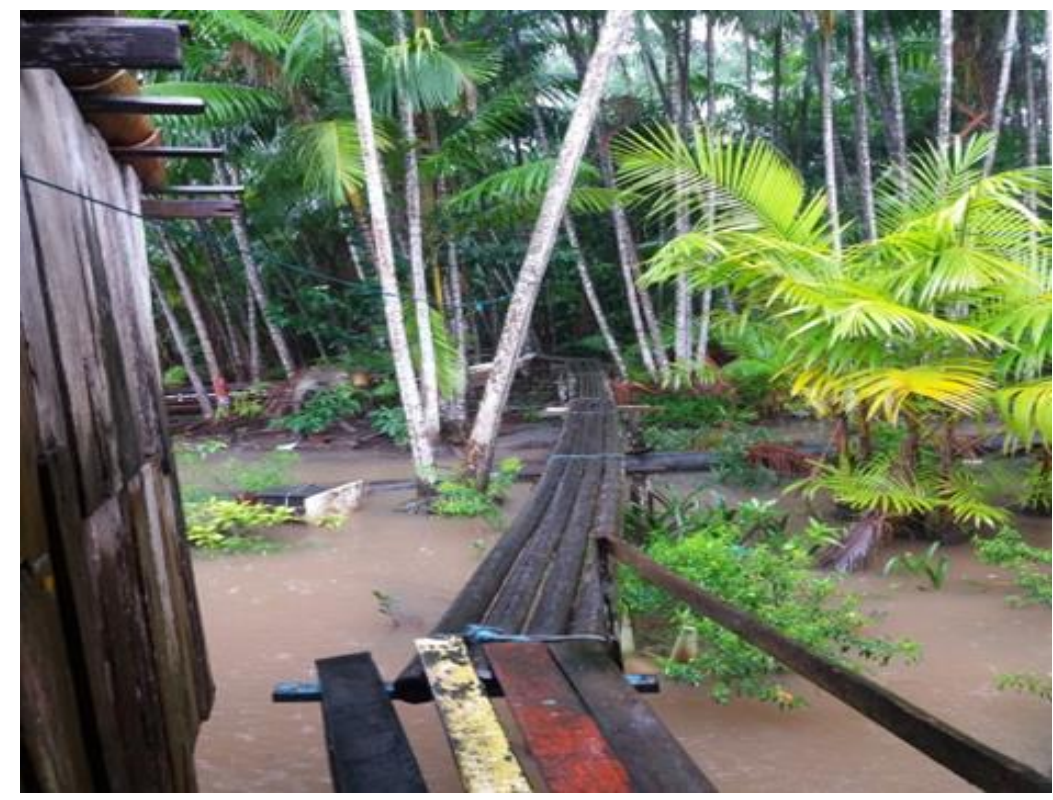

Fonte: Autora (2020).

Esta Unidade Pedagógica se recente assim de uma formação que aponte para temas geradores de reflexão em torno da realidade dos alunos. A formação inicial ou continuada de professores precisa estar antes de mais nada com o olhar voltado para a sua territorialidade, o que traz diversidades, identidades, cultura vivida especificas, particulares deste território amazônico em que estamos situados não somente com uma dimensão local, mas a força social, ecológica que nos 
envolve e nos faz ter a responsabilidade sobre ele trazendo para as salas de aula este olhar de compromisso.

Percebesse na atuação dos professores nesta Unidade Pedagógica a preocupação em estabelecer relação do contexto ribeirinho nas aulas, onde as crianças contam as histórias vivenciadas por elas e seus familiares. Fazem relação cos elementos apresentados nos livros didáticos e os vivenciados em seu contexto ribeirinho, mostram que há um deslocamento do social para o pedagógico. Sendo acolhido pelos professores.

O que pode-se buscar para superar os desafios da Educação Básica é a formação de professores e atuação destes profissionais numa perspectiva intercultural como aponta Fleuri (2018, p. 45) "O que está em jogo na formação dos educadores é a superação da perspectiva monocultural e etnocêntrica que configura os modos tradicionais e consolidados de educar, a mentalidade pessoal, os modos de se relacionar com os outros e de atuar nas situações concretas" onde as diversidades possam estar sendo vividas e essas diferenças estejam harmonizadas em uma relação de respeito, valorização e dignidade.

\section{PARA QUE AS ÁGUAS INUNDEM OS CAMINHO...}

Cada território com suas redes de sociabilidade traz em si maneiras, saberes, maresias de convivência, a Amazônia poderia estar universalmente conectada assim como intimamente voltada somente para o seu ecossistema, porém educar na Amazônia é pensar em sua preservação, é ter um olhar de mundo, para o mundo e com este defende-la por ela e por todos nós.

A redescoberta dessa dimensão mundial que é a Amazônia para o mundo precisa estar nas salas de aula, a educação precisa fazer um pacto social com os todos os atores envolvidos em seus palcos, as salas de aula. Uma visão ecológica do saber refresca, ondula para ações de valorização do ser, do saber e do viver em conexões insulares encontrando novos significados nesta relação com a diversidade, com as identidades, culturas, de gênero, de etnias, entre outras.

A educação deve ir para as águas e fazer a sua cultura vivida vir à tona, emergir, visibilizar este cotidiano, para buscar contribuir com a produção de novas 
propostas curriculares que vá ao encontro dos interesses das populações que vivem à margem dos rios e também a margem da sociedade, porém soberana em suas vivencias, identidades. A diversidade das águas ondulam por todos os lados.

Educar na Amazônia é dar voz ao povo das águas que no seu cotidiano criam rastro de saberes para dentro da escola, onde mesmo que não institucionalmente um currículo específico das e para as escolas ribeirinhas seja referenciado os professores desta Unidade Pedagógica se esforçam para isso, os alunos letram sua cultura por dentro do que a escola traz para eles e os moradores das ilhas pesquisadas valorizam a escola dando a ela uma lugar de excelência. 


\section{REFERÊNCIAS}

BRANDÃO, C. R. Cenário e momentos da vida camponesa: três dias de caderno de campo em uma pesquisa no Pretos de Baixos do Bairro dos Pretos, em Joanóplolis. São Paulo, 2003.

BHABHA, H. K. O local da cultura. Tradução de Myrian Áila, Eliana Lourezo de Lima Reis, Gláucia Renate Gonçalves. 2 ed. Beo Horizonte: Editora UFMG. 2013.

BRASIL. Ministério da Educação e Cultura. Parâmetros Curriculares Nacionais: pluralidade cultural e orientação sexual. Brasilia:MEC/SEF,1997,164p.

CARVALHO, M.S. As águas da cultura vivida inundando a educação: uma leitura sobre letramentos e cultura ribeirinha. Dissertação (dissertação em Educação). UFPA. Belém, p.105. 2018.

COSTA, M.V. Currículo e Política cultural. In: Idem, org. 0 currículo nos limiares do contemporâneo. Rio de Janeiro: DP\&A, 1998

FLEURI, R. M. Educação Intercultural e Formação de professores. João Pessoa: Editora do CCTA, 2018. 303p.

FREIRE, P. Conscientização: teoria e prática da libertação: uma introdução ao pensamento de Paulo Freire. ed. 3. São Paulo. Moraes. 1980.

A pedagogia do oprimido. 19 ed.Rio de Janeiro: Paz e terra, 1987.

GIROUX. H.A. Praticando estudos Culturais nas Faculdades de Educação. In: SILVA, T.T da. (org.) Alienígenas na sala de aula. 8 ed. Petrópolis Rj: Vozes. 2009 (coleção Estudos Culturais em Educação).

NANNI, A. L' educazione interculturaleoggiin Italia. Brescia: EMI. 1998.

OLIVEIRA, I. A. Epistemologia e educação: bases conceituais e racionalidades científicas e históricas. Petrópolis, RJ: Vozes, 2016.

OLIVEIRA, L F.de. História da africa e dos africanos na escola: desafios políticos e epistemológicos e identitários para a formação dos professores de história. Rio de Janeiro: Imperial Novo Milênio, 2012.

SANTOMÉ, J.J. As culturas negadas e silenciadas no currículo. In: SILVA, T.T da. (org.) Alienígenas na sala de aula. 8 ed. Petrópolis Rj: Vozes. 2009 (coleção Estudos Culturais em Educação).

PAIXÃO, C. J; NUNES, C C. No território do Ensino Fundamental: demarcações na cultura curricular como experiência vivida dos professores. Revista e-curiculum, São Paulo, vol. 13, n. 03, p. 519-533, Set. 2015. 
Educação Básica na Amazônia: as águas da diversidade...

SILVA, T. T. da. Documentos de identidade: uma introdução às teorias de currículo. ed. 3. Editora Autêntica, 2010. 